\title{
The Influence of School Loose-Tight Culture on Bullying of Middle School Students: The Mediating Role of Collective Moral Disengagement and Collective Efficacy
}

\author{
Lei Wang, Yirui Song \\ Wuhan Sports University, Wuhan 430079, Hubei, China
}

\begin{abstract}
To explore the relationship and mechanism of school loosetight culture to middle school bullying, a total of 808 students were selected from three middle schools in Dehong Prefecture, Yunnan Province of China, to conduct a questionnaire survey. The study used the school loose-tight culture scale, the collective moral disengagement scale, the collective efficacy scale, and the bullying scale for middle school students. The results showed that (i) school loose-tight culture significantly predicted the occurrence of school bullying; (ii) school loose-tight culture was significantly negatively correlated with collective moral disengagement and school bullying but positively correlated with collective efficacy. Further, collective moral disengagement was significantly positively correlated with school bullying, but collective efficacy was significantly negatively correlated with school bullying; (iii) school loose-tight culture inhibited school bullying through the dual mediating effects of collective moral disengagement and collective efficacy at the same time.
\end{abstract}

Best Evidence in Chinese Education 2021; 9(2):1263-1272.

Doi: 10.15354/bece.21.ar060.

How to Cite: Wang, L., \& Song, Y. (2021). The influence of school loose-tight culture on bullying of middle school students: The mediating role of collective moral disengagement and collective efficacy. Best Evidence in Chinese Education, $9(2): 1263-1272$.

Keywords: School Loose-Tight Culture, Collective Moral Disengagement, Collective Efficacy, Campus Bullying 
Wang \& Song. Influence of School Loose-Tight Culture on Bullying of Middle School Students.

About the Author: Yirui Song, Department of Psychology, Wuhan Sports University, Wuhan 430079, Hubei, China. E-mail:804504354@qq.com

Correspondence to: Lei Wang, Associate Professor, Department of Psychology, Wuhan Sports University, Wuhan 430079, Hubei Province, China.E-mail:378299706@qq.com

Funding: This work was supported by the National Social Science Fund Project "Mental Generation Mechanism and Intervention Research on Campus Violence in Middle School Students” (project \#: 16BSH104).

Conflict of Interests: None.

() 2021 Insights Publisher. All rights reserved.

(c) (i) (S) Creative Commons Non Commercial CC BY-NC: This article is distributed under the terms of the Creative Commons Attribution-NonCommercial 4.0 License

(http://www.creativecommons.org/licenses/by-nc/4.0/) which permits non-commercial use, reproduction and distribution of the work without further permission provided the original work is attributed by the Insights Publisher. 


\section{Question}

$\mathrm{S}$

CHOOL bullying is considered a widespread form of school violence, which has a long-term negative impact on young people's healthy personalities and development (Hu, 2017). Studies have shown that students with externalized behavior problems react negatively to the external environment (Cai, 2006). First, according to the ternary interaction theory, an individual's behavior is strongly governed by motivation and beliefs and adversely affects the subject's thinking and emotions. Secondly, behavior is not only governed by individual needs but also restricted by the environment. Schools and classes are the environments that middle school students are exposed to most frequently, directly impacting their behavior. Studies have shown that bullying behaviors of middle school students are related to factors such as moral disengagement, self-efficacy, and class environment (Wang et al., 2018). Still, there is no research on the influencing factors of campus bullying from the collective level. According to the ecological system theory, the development of middle school students is in a complex environmental system, and each layer of the system interacts with other systems and individuals, which affects the development of students. School culture is the core force that promotes the development of the school and the internal mechanism that affects students' behavior. Therefore, it is feasible and significant to discuss the impact of school culture on campus bullying from the collective level.

Tight-loose culture is a new dimension of cross-cultural psychology research, which refers to the social norm culture of punishment and intensity of deviant behaviors (Lu et al., 2017). The "loose" in tight-loose culture refers to weak norms and a high tolerance for deviant behaviors (inadequate punishment), and "tight" refers to solid norms and a low tolerance for deviant behaviors (intense punishment) (Gelfand, Li \& Gordon, 2017). Social norms under different cultural backgrounds reflect the difference between looseness and tightness, which helps to enhance our understanding and prediction of differences in human psychology and behavior. Under different school cultural backgrounds, students perceive different school loose-tight cultures, and their selfcontrol, self-regulation, and self-monitoring abilities for bullying behavior are also quite different. Studies have shown that students are prone to frequent skipping classes in schools with relatively loose rules and regulations. Students cannot be better integrated into the class environment, leading to increased bullying behavior (Zeng et al., 2019). As a result, school loose-tight culture directly impacts campus bullying, and this impact will play a role indirectly through the class atmosphere.

Studies have shown that moral disengagement has a significant positive predictive effect on adolescent verbal bullying, relationship bullying, and physical bullying (Yang \& Wang, 2012). Bandura (2002) put forward the concept of collective moral disengagement, which refers to the common belief of the group that defends negative behaviors morally, and it reflects the degree of recognition or opposition of the class to certain irregular behaviors. As a collective consensus, collective moral disengagement is more likely to transfer responsibility, which in turn increases the possibility of campus bullying. The lower the middle school students' perception of the school atmos- 
phere, the higher their level of moral disengagement. Collective efficacy is proposed by Bandura based on self-efficacy and defines it as to whether people feel that they can solve problems through joint efforts in a group, organization, or country, and increase the strength of belief in life. Studies have shown a negative correlation between individual self-efficacy and bullying behavior, and individuals with low self-efficacy are more likely to have bullying behavior (Valois et al., 2017). Studies have pointed out that student problem behaviors are significantly related to class collective efficacy, and students with lower collective efficacy levels are bullied more frequently (Sapouna, 2010). Social norms run through the entire human culture and are a collective consensus of human beings on acceptable behavior. Collective moral disengagement and collective efficacy, as a collective consensus of class environment and school belonging, may affect students' bullying behavior.

School culture has a particular influence on campus bullying. In addition, collective moral disengagement and collective efficacy, as an individual's perception of class atmosphere, also impact campus bullying behavior. According to ecosystem theory, school loose-tight culture will affect the class atmosphere, and the class atmosphere will further affect campus bullying. Therefore, the relationship between school loosetight culture, collective moral disengagement, collective efficacy, and the occurrence of campus bullying is worthy of attention. This study aims to test the relationship between these variables to provide a reference for the prevention and intervention of school bullying.

\section{Methodology}

\section{Survey Object}

Using the convenient sampling method, a total of 850 middle school students were selected from three middle schools in Dehong Prefecture, Yunnan Province of China. After excluding 42 invalid data, 808 valid data were finally obtained, with an effective rate of $95.1 \%$. Among them, there are 353 boys (43.7\%) and 455 girls $(56.3 \%)$; there are $276(34.2 \%)$ students in the 7th grade, $238(29.5 \%)$ in the 8th grade, and $294(36.3 \%)$ in the 9 th grade.

\section{Research Tools}

\section{- School Loose-Tight Culture Scale}

This study used the school loose-tight culture scale compiled by Gelfand et al. (2011), with a total of 6 items. A Likert 6-point scoring is used, from 1 for "completely disagree" to 6 for "completely agree. The higher the score, the "tighter" the school loose-tight culture perceived by the students. The Cronbach's $\alpha$ coefficient of the scale in this study was 0.86 .

\section{- School Bullying Moral Disengagement Scale}


This study used the Moral Disengagement Scale of Campus Bullying compiled by Thornberg et al. The Chinese version was revised by Wang, Yan \& Qiu (2019). There are 30 items in the scale divided into eight dimensions: moral defense, distorted results, dehumanization, responsibility transfer, scattered responsibility, euphemistic labeling, favorable comparison, and blame attribution. Use a 5-point scale of 1-5. The higher is the score, and the higher is the level of campus bullying moral disengagement. The Cronbach's $\alpha$ coefficient of the scale in this study was 0.91 .

\section{- Collective Efficacy Scale}

This study used the collective efficacy scale compiled by Goddard (2002), with 12 tems in total. It is divided into two factors: task analysis and group structure. Using a 5-point scale of 1-5, and the higher is the score; the higher is the students' collective efficacy. The Cronbach's $\alpha$ coefficient of the scale in this study was 0.87 .

\section{- Bullying Scale for Middle School Students}

Using Yang's (2014) bullying scale for middle school students, there are 14 items in total, divided into two subscales: bullying and being bullied. The scale uses a 5-point scale of 1-5. The Bullying Scale has seven items, and the higher the score, the higher the frequency of bullying; the Bullied Scale has seven items and the higher the score, the higher the degree of being bullied. The Cronbach's $\alpha$ coefficient of the bullying subscale and the being bullied subscale in this study were 0.89 and 0.85 , respectively.

\section{Data Processing and Collection}

Use SPSS25.0 for reliability test, single factor common method deviation test, descriptive statistics, and correlation analysis. In addition, Mplus7.4 established the structural equation model, and the mediation effect test of the percentile Bootstrap method with deviation correction was carried out.

\section{Results and Analysis}

\section{Common Method Deviation Test}

Harman's single factor test method was used to perform unrotated EFA on all the original items of the main variables in this study. The test results found that the explanatory rate of the first common factor was $14.28 \%$, which did not exceed the critical value of $40 \%$. Therefore, this result indicated that no serious common method deviation existed in this study.

\section{Descriptive Statistics}

Descriptive statistics and Pearson correlation analysis were performed on school loosetight culture, collective moral disengagement, collective efficacy, and school bullying (Table 1). The results showed that school bullying was significantly negatively corre- 
Table 1. Correlation Analysis of School Bullying and School Loose-Tight Culture, Collective Moral Disengagement, and Collective Efficacy.

\begin{tabular}{|c|c|c|c|c|c|}
\hline Variable & $M \pm S D$ & $\begin{array}{l}\text { School } \\
\text { Loose-Tight } \\
\text { Culture }\end{array}$ & $\begin{array}{l}\text { Collective } \\
\text { Moral } \\
\text { Disengagement }\end{array}$ & $\begin{array}{l}\text { Collective } \\
\text { Efficacy }\end{array}$ & Bullying \\
\hline $\begin{array}{l}\text { School } \\
\text { Loose-Tight } \\
\text { Culture }\end{array}$ & $4.52 \pm 0.93$ & 1 & & & \\
\hline $\begin{array}{l}\text { Collective } \\
\text { Moral } \\
\text { Disengagement }\end{array}$ & $2.09 \pm 0.65$ & $-0.17^{\star *}$ & 1 & & \\
\hline $\begin{array}{l}\text { Collective } \\
\text { Efficacy }\end{array}$ & $3.58 \pm 0.58$ & $0.31^{\star *}$ & $-0.28^{* *}$ & 1 & \\
\hline Bullying & $1.71 \pm 0.81$ & $-0.21^{* *}$ & $0.28^{* *}$ & $-0.33^{\star *}$ & 1 \\
\hline Being Bullied & $1.34 \pm 0.65$ & $-0.15^{\star *}$ & $0.31^{* *}$ & $-0.28^{\star *}$ & $0.53^{* *}$ \\
\hline
\end{tabular}

Table 2. Analysis of the mediating effect of collective moral disengagement and collective efficacy.

\begin{tabular}{llllllll}
\hline & \multirow{2}{*}{$\begin{array}{l}\text { Effect } \\
\text { Size }\end{array}$} & $\begin{array}{l}\text { Boot } \\
\text { SE }\end{array}$ & $\mathbf{Z}$ & $\mathbf{p}$ & & \multicolumn{2}{c}{ U5\% Cl } \\
\cline { 6 - 8 } & -0.25 & 0.04 & -5.53 & $<0.001$ & -0.34 & -0.16 \\
\hline Overall Effect & -0.22 & 0.03 & -5.90 & $<0.001$ & -0.30 & -0.16 \\
\hline Indirect Effect & -0.07 & 0.02 & -3.55 & $<0.001$ & -0.11 & -0.03 \\
\hline $\begin{array}{l}\text { School Loose-Tight Culture } \rightarrow \\
\begin{array}{l}\text { Collective Moral Disengagement } \\
\text { School Bullying }\end{array}\end{array}$ & & & & & & \\
\hline $\begin{array}{l}\text { School Loose-Tight Culture } \rightarrow \\
\begin{array}{l}\text { Collective Efficacy } \rightarrow \\
\text { School Bullying }\end{array}\end{array}$ & -0.15 & 0.03 & -4.84 & $<0.001$ & -0.23 & -0.10 \\
\hline Direct Effect & -0.03 & 0.02 & -0.52 & 0.61 & -0.13 & 0.08 \\
\hline
\end{tabular}

lated with school loose-tight culture, significantly positively correlated with collective moral disengagement, and significantly negatively correlated with collective efficacy. School loose-tight culture has a significant negative correlation with collective moral disengagement and a significant positive correlation with collective efficacy. Furthermore, bullying is positively associated with being bullied. This showed that school bullying is obviously affected by school loose-tight culture perception, collective moral disengagement, and collective efficacy. 


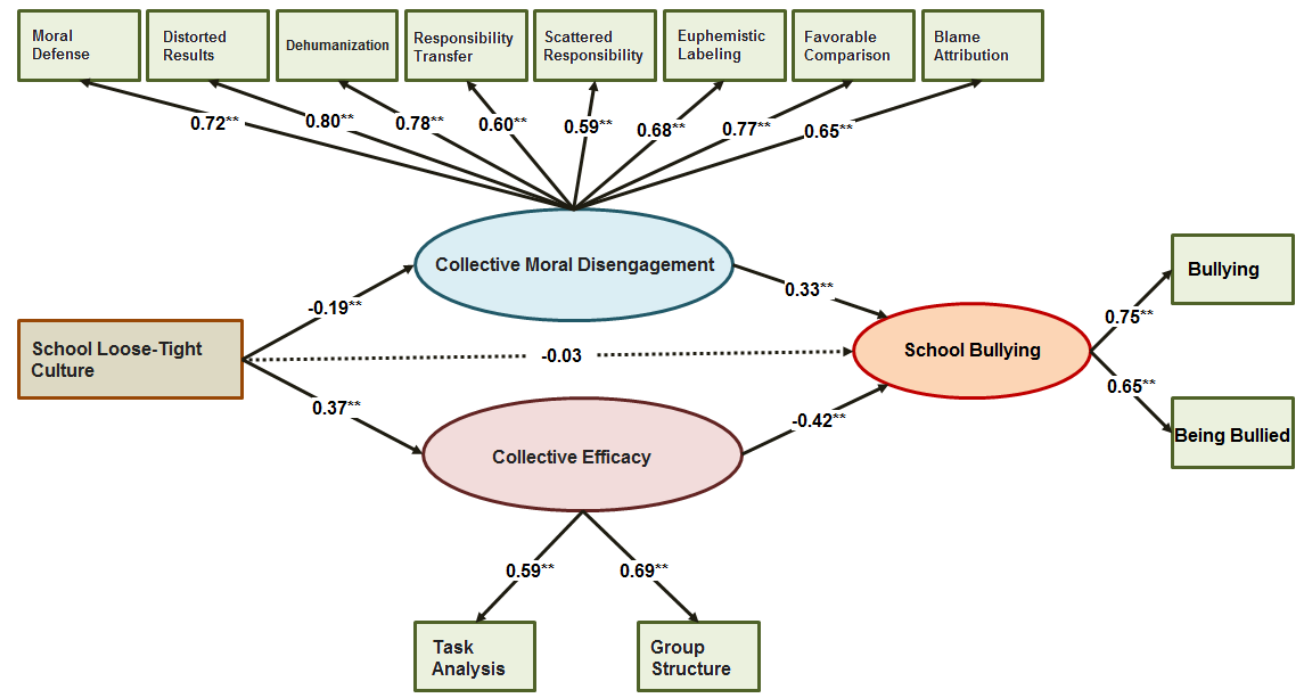

Figure 1. The Mediation Model of School Loose-Tight Culture Affecting School Bullying.

\section{The Mediating Role of Collective Moral Disengagement and Collective Efficacy in the Relationship between School Loose-Tight Culture and School Bullying}

Structural equation modeling was used to analyze the multiple mediating effects of collective moral disengagement and collective efficacy between school loose-tight culture and campus bullying (Figure 1). Each fitting index of the model reached a critical value $\left(\chi^{2} / \mathrm{df}=3.64, \mathrm{CFI}=0.95, \mathrm{TLI}=0.94, \mathrm{RMSEA}=0.06\right)$. According to the Bootstrap method recommended by Wen and Ye (2014) to further test the significance of the mediation effect. The results show that the mediating effects of collective moral disengagement and collective efficacy are both significant, and the parallel mediating effects of collective moral disengagement and collective efficacy in school loosening culture and campus bullying are significant.

The total effect of school loose-tight culture on school bullying was -0.25 . After the model introduces collective moral disengagement and collective efficacy, the direct effect changed to -0.03 ; the indirect effect of collective moral disengagement and collective efficacy in the impact of school bullying on school loose-tight culture was 0.22 , and the effect amount (that is, the mediation effect accounts for the total effect percentage) was $88 \%$. School loose-tight culture had an indirect effect on campus bullying through collective moral disengagement, with a size of -0.07 , accounting for $28 \%$ of the total effect. School loose-tight culture could also indirectly affect bullying behavior 
through collective efficacy, with a size of -0.15 , accounting for $60 \%$ of the overall effect (Table 2).

\section{Discussion}

This study aimed to explore the impact of school loose-tight culture on campus bullying, and the mediating mechanism of collective moral disengagement and collective efficacy. Correlation analysis showed that school loose-tight culture is significantly negatively correlated with school bullying; further structural equations showed that school loosetight culture negatively predicts school bullying. The finding is consistent with previous research results (Wang et al., 2017) and further proved the negative predictive effect of school loose-tight culture on campus bullying. Collective moral disengagement is significantly positively correlated with campus bullying; collective efficacy is significantly negatively correlated with campus bullying. This result validates our hypothesis and is also in line with the moral disengagement theory. When individuals have externalized behavior problems, they will first reduce psychological guilt and self-blame through the mechanism of moral disengagement (Gutzwiller-Helfenfinger, 2015). According to social cognition theory, when individuals pursue goals, self-efficacy affects behavior changes through physical arousal and is cultivated by individuals in the social environment. In the same way, collective efficacy is a way of cognition cultivated by individuals in a group environment and affects their bullying behavior.

Our results showed that collective moral disengagement plays a completely mediating role between school loose-tight culture and campus bullying. On the one hand, moral disengagement is a crucial internal mechanism for psychological abuse and neglect to affect adolescent bullying behavior. On the other hand, school culture is the norms, rules, atmosphere, and way of thinking jointly created by teachers, students, and school administrators in the long-term educational and teaching activities through the interaction between the school members. School culture provides students with ethical requirements, lists clear rules and regulations, and determines what behaviors students can do and what is out of school management treaties. These can effectively reduce the occurrence of collective moral disengagement. On the other hand, when the level of moral disengagement is higher, the collective will transfer more responsibility, thereby perceiving less attribution of blame and lowering the victim's painful perception, which ultimately leads to campus bullying, consistent with previous studies (Sun et al., 2017). Therefore, we must not only pay attention to the cultivation of the school cultural environment, but also prevent the negative effect of collective moral disengagement in the class environment.

Collective efficacy plays a completely intermediary role between school loosetight culture and campus bullying. In collective cognition development, group identity, collective efficacy, and group emotions will change with social situations and group conditions. When students perceive the "tight" school culture atmosphere, the level of collective efficacy will increase, and group members are more willing to participate in joint actions. Students have improved their interpersonal relationships through cooperation and communication, and the intervention on campus bullying will also increase, 
which has a certain inhibitory effect on bullying. Therefore, improving the level of collective effectiveness can effectively reduce the probability of school bullying incidents.

The research results showed that there is a significant negative correlation between collective moral disengagement and collective efficacy. Collective moral disengagement and collective efficacy, as a collective consciousness, as the class environment and atmosphere, are closely linked to the school culture, forming an ecological environment system that connects the school and the class and profoundly impacts the bullying behavior of students.

The study results confirmed that the school loose-tight culture reduces school bullying by reducing collective moral disengagement and enhancing collective efficacy. Thus, introducing the loose-tight cultural dimension in cross-cultural psychology has practical significance for advancing the localization of campus bullying. Therefore, in the future, we can pay attention to campus bullying and the level of students' mental health from the overall ecosystem level of individual-collective, home-school connection, and so on.

\section{References}

Bandura, A. (2002). Selective moral disengagement in the exercise of moral agency. Journal of Moral Education, 31(2):101-109.

Available at: https://psycnet.apa.org/doi/10.1080/0305724 022014322

Cai, C.F., \& Zhou, Z.K. (2006). A study on the behavioral stability of children with external problems. Advances in Psychological Science, 14(1):66-72. DOI:

http://dx.doi.org/10.3969/j.issn.16713710.2006.01.011

Gelfand, M.J., Li, R., \& Gordon, S. (2017). Tightness-looseness and consumer behavior: The road ahead. Journal of Consumer Psychology, 27(3):405-407. DOI: http://dx.doi.org/10.1016/j.jcps.2017.05.001

Gelfand, M.J., Raver, J.L., Nishii, L., Leslie, L.M., Lun, J., Lim, B.C., Duan, L.,

Almaliach, A., Ang, S., Arnadottir, J., Aycan, Z., Boehnke, K., Boski, P., Cabecinhas, R., Chan, D., Chhokar, J., D'Amato, A., Ferrer, M., Fischlmayr, I.C., Fischer, R., Fülöp, M.,
Georgas, J., Kashima, E.S., Kashima, Y., Kim, K., Lempereur, A., Marquez, P., Othman, R., Overlaet, B., Panagiotopoulou, P., Peltzer, K., Perez-Florizno, L.R., Ponomarenko, L., Realo, A., Schei, V., Schmitt, M., Smith, P.B., Soomro, N., Szabo, E., Taveesin, N., Toyama, M., Van de Vliert, E., Vohra, N., Ward, C., \& Yamaguchi, S. (2011). Differences between tight and loose cultures: A 33-nation study. Science, 332(6033):1100-1104. DOI: https://doi.org/10.1126/science.1197754

Goddard, R.A. (2002). Theoretical and empirical analysis of the measurement of collective efficacy: The development of a short form. Educational and Psychological Measurement, 62(1): 97-110. DOI: https://doi.org/10.1177\%2F00131644020620 $\underline{01007}$

Gutzwiller-Helfenfinger, E. (2015). Moral disengagement and aggression: Comments on the special issue. Merrill-Palmer Quarterly, 61(1):192-211. DOI: 
Wang \& Song. Influence of School Loose-Tight Culture on Bullying of Middle School Students.

https://doi.org/10.13110/merrpalmquar1982. $\underline{61.1 .0192}$

Hu, C.G. (2017). Campus bullying: meaning, causes and prevention strategies. Educational Research and Experiment, 2017(1):73-79.

Lu, J., Chen, H., \& Le, G.A. (2017). Loose-tight culture: A new dimension of cross-cultural psychology research. Advances in Psychological Science, 25(5):887-902. Available at: http://journal.psych.ac.cn/xlkxjz/CN/10.372 4/SP.J.1042.2017.00887

Sapouna, M. (2010). Collective efficacy in the school context: Does it help explain victimization and bullying among Greek primary and secondary school students? Journal of Interpers Violence, 25(10):1912-1927 http://dx.doi.org/10.1177/088626050935450 $\underline{9}$

Sun, L.J., Heng, S.P., Niu, G.F., Li, J.Y., Du, H.Q., \& Hu, X.G. (2017). The influence of childhood psychological abuse on adolescent aggressive behavior: The mediating effect of security and loneliness. Chinese Journal of Clinical Psychology, 25(5).

Valois, R.F., Zullig, K.J., \& Revels, A.A. (2017). Aggressive and violent behavior and emotional self-efficacy: Is there a relationship for adolescents? Journal of School Health, 87(4):269-277. DOI:

https://doi.org/10.1111/josh.12493

Wang, J.Y., Yan, X.C. \& Yan, H.X. (2017). Campus ethics analysis and construction of campus bullying phenomenon. Journal of Chinese Education, 2017(3):54-60. Available at:

http://www.jcse.com.cn/CN/Y2017/V0/I3/54
Wang, L., Xing, S.Y., X.Y.Y., \& Chen, J. (2018). The influence of class environment on violent behavior of middle school students: the mediating effect of moral refusal. Educational Research and Experiment, 2018(5):88-91.

Wang, X.F., Yan, L.S., \& Qiu, X.Y. (2019). Reliability and validity test of the school bullying moral rejection scale in domestic middle school students. Chinese Journal of Clinical Psychology, 27(1):54-58.

Wen, Z.L., \& Ye, B.J. (2014). Mediating effect analysis: Method and model development. Advances in Psychological Science, 22(5):731-745.

Yang, J.P., \& Wang, X.C. (2012). The influence of moral refusal on adolescents' aggressive behavior: A moderated mediating effect. Psychological Bulletin, 44(8):1075-1085. Available at: http://journal.psych.ac.cn/xlxb/CN/Y2012/V 44/I8/1075

Yang, W.M. (2014). Research on the Influencing Factors of Middle School Students' Bullying Behavior: Based on Multi-layer Analysis of HLM Model. Zhejiang: Master's Thesis of Zhejiang Normal University.

Zeng, X.R., Wang, Y., Ding, J.H., \& Zhou, H. (2019). Classroom bullying norms and bullying behavior: The mediating effect of group fear and peer pressure. Psychology News, 51(8):935-944. DOI: http://dx.doi.org/10.3724/SP.J.1041.2019.00 $\underline{935}$

Received: 29 September 2021

Revised: 07 October 2021

Accepted: 25 October 2021

The Chinese version of this article has been published in Educational Research and Experiment, 2021,1:93-96. The English version has been authorized for being publication in BECE by the author(s) and the Chinese journal.

王否, 宋一锐. (2021). 学校松-紧文化对中学生欺凌的影响: 集体道德推脱与集体效能感的中 介作用. 教育研究与实验, 1:93-96. 